Modern Physics Letters B

(c) World Scientific Publishing Company

\title{
ERRATUM
}

\section{HYDROGENIC SLATER RADIAL INTEGRALS WITH DISCRETE PARAMETERS AND THEIR ASYMPTOTICS}

\author{
[Mod. Phys. Lett. B, Vol. 8, No. 23 (1994) 1403-1416] \\ V. F. TARASOV
}

On p. 1404, the expression for $A_{i}$ on the line under Eq. (5) should read as

$$
A_{i}=(-a)_{i}(q)_{i} /\left((c)_{i}(1)_{i}\right)
$$

